\title{
Influence of the Space Charge on Tunneling of Electrons and Their Conductivity by the Resonance Tunneling Structures in the Constant Electric Field
}

\author{
I.V. Boyko, M.R. Petryk \\ Ternopil National Technical University, 56, Ruska Str., 46001 Ternopil, Ukraine
}

(Received 30 January 2017; revised manuscript received 23 May 2017; published online 30 June 2017)

\begin{abstract}
The quantum mechanical theory of spectral parameters and dynamic conductivity of electrons, interacting with field of the created by them space charge in open flat resonance tunneling structure with a constant electric field in the model of rectangular potential wells and barriers has been developed. The influence of space charge on the conductivity of the experimentally realized nanostructures as the active region of a quantum cascade laser for different concentrations of electrons in the falling on the resonance tunneling structure beam, has been investigated.
\end{abstract}

Keywords: Resonant-tunneling structure, Quantum cascade laser, Static charge, Dynamic charge, Dynamic conductivity.

\section{INTRODUCTION}

One of the directions which is still developing now, is the study of dissipative processes affecting the process of electron tunneling in open multilayer resonance tunneling structures (RTS), which act as active elements of quantum cascade lasers (QCL) [1, 2] and detectors [3]. These processes are caused by the electronelectron interaction and interaction of electrons with phonons and impurities. The effect of electron-electron interaction on electron tunneling was investigated in the paper [4]. The electron-phonon interaction and the influence of phonons on the electronic spectrum were studied in the works [5-7]. The effect of static and dynamic charge fields generated by electrons on the electron transport in open RTS is studied poorly. Similar works taking into account the effect of static space charge on the electrons spectrum in closed RTS have been considered in [8, 9]. However, the self-consistent impact of static and dynamic spatial charges on the tunneling of electrons interacting with time-dependent electromagnetic field was studied in $[10,11]$ in a very rough model of RTS with $\delta$-like potential barriers.

In the proposed paper the theory of electronic transport through the three-barrier RTS with applied constant longitudinal electric field based on the found self-consistent solution of full Schrödinger equation and the Poisson's equation has been developed. Basing on the three-barrier RTS as the active region of the experimentally realized QCL with $\operatorname{In}_{1-x} G_{x} A s$ - wells and $\operatorname{In}_{1}$. ${ }_{x} \mathrm{Al}_{\mathrm{x}} \mathrm{As}$ - barriers the influence of spatial static and $\mathrm{dy}-$ namic charges on the spectral parameters of quasistationary states (QSS) of the electrons and active dynamic conductivity of nanostructure.

\section{SELF-CONSISTENT SCHRÖDINGER AND POISSON EQUATIONS. THEORY OF DYNAM- IC CONDUCTIVITY OF THREE-BARRIER RESONANCE TUNNELING STRUCTURE}

To calculate the active dynamic conductivity of electrons by three-well active region of QCL we assume that the nanostructure in the Cartesian coordinates is located so, that layers are perpendicular to the boundaries heteroboundaries of nanosystem. Perpendicular to the layers of RTS constant electric field with intensity $\vec{F}$ is applied. The geometric parameters of nanosystem are known (Fig. 1).

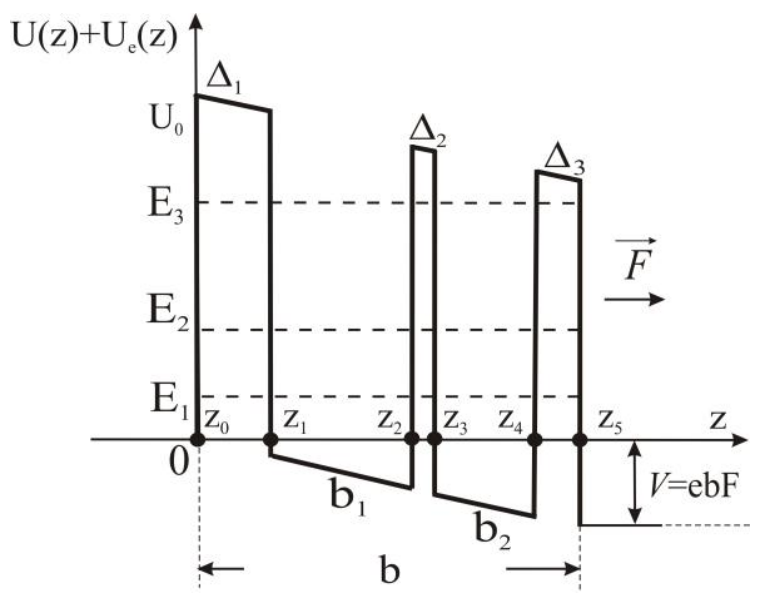

Fig. 1 - Geometric and energy schemes of the three-barrier RTS

Since the difference between lattice constants of well and barrier layers is insignificant, the model of effective masses and rectangular potentials is used for electron:

$$
\begin{gathered}
m(z)=m_{w}\left[\theta(-z)+\sum_{p=1}^{3}\left(\theta\left(z-z_{2 p-1}\right)-\theta\left(z-z_{2 p}\right)\right)\right]+m_{b} \sum_{p=0}^{2}\left[\theta\left(z-z_{2 p}\right)-\theta\left(z-z_{2 p+1}\right)\right], \\
U(z)=U \sum_{p=0}^{2}\left[\left(\theta\left(z-z_{2 p}\right)-\theta\left(z-z_{2 p+1}\right)\right]-e F\left\{z\left[\theta(z)-\theta\left(z-z_{5}\right)\right]+z_{5} \theta\left(z-z_{5}\right)\right\}\right.
\end{gathered}
$$


where $\theta(z)$ - Heaviside function, $z_{1} \rightarrow-\infty, z_{6} \rightarrow \infty ; m_{\omega}$ and $m_{b}$ - effective mass of electron in the potential wells and barriers of nanostructure respectively.

It is assumed, that mono-energetic current of electrons with energy $E$ and initial concentration $n_{0}$ falls

$$
i \hbar \frac{\partial \Psi(z, t)}{\partial t}=\left(-\frac{\hbar^{2}}{2} \frac{\partial}{\partial z} \frac{1}{m(z)} \frac{\partial}{\partial z}+U(z)+H(z, t)\right) \Psi(z, t), .
$$

- where

$$
H(z, t)=-e \Theta\left[z \theta(z)+\left(z_{5}-z\right) \theta\left(z-z_{5}\right)\right]\left(e^{i \omega t}+e^{-i \omega t}\right)+e \varphi(z, t),
$$

Hamiltonian, the first term of which describes the time-dependent electromagnetic field with frequency $\omega$ and amplitude of its electric component $\epsilon$, and the second term describes the interaction of the electron with the field of space charge, potential $\varphi(z, t)$ of which

is determined by the Poisson's equation:

$$
\frac{\partial}{\partial z}\left[\varepsilon(z) \frac{\partial \varphi(z, t)}{\partial z}\right]=-4 \pi e n(z, t)
$$

- where

$$
\varepsilon(z)=\varepsilon_{w}\left(\theta(-z)+\sum_{p=1}^{3}\left(\theta\left(z-z_{2 p-1}\right)-\theta\left(z-z_{2 p}\right)\right)\right)+\varepsilon_{b} \sum_{p=0}^{2}\left(\theta\left(z-z_{2 p}\right)-\theta\left(z-z_{2 p+1}\right)\right)
$$

- dielectric permeability of three-barrier TRS, $\varepsilon_{\omega}$ and $\varepsilon_{b}$ - dielectric permeability of the potential well and barrier layers material correspondingly,

$$
n(z, t)=n_{0}|\Psi(z, t)|^{2}
$$

is variable in space electrons concentration.

It is seen from the equations (3) and (5), taking into account Hamiltonian (4) and relation (7), that they form self-consistent system.
Solution of full Schrödinger equation (3) with Hamiltonian (4) in the weak signal approximation is found as:

$$
\begin{gathered}
\Psi(z, t)=\Psi_{0}(z) e^{-i \omega_{0} t}+\Psi_{-1}(z) e^{-i\left(\omega_{0}-\omega\right) t}+ \\
+\Psi_{+1}(z) e^{-i\left(\omega_{0}+\omega\right) t}, \quad \omega_{0}=E / \hbar
\end{gathered}
$$

Having substituted the relation (7) in the Poisson's equation (5) taking into account (8) we obtain:

$$
\frac{\partial}{\partial z}\left[\varepsilon(z) \frac{\partial \phi(z, t)}{\partial z}\right]=-4 \pi e n_{0}\left[\xi_{0}(z)+\xi(z) e^{i \omega t}+\xi^{*}(z) e^{-i \omega t}\right]
$$

where

$$
\begin{aligned}
& \xi_{0}(z)=\left|\Psi_{0}(z)\right|^{2} \\
& \xi_{+}(z)=\Psi_{0}(z) \Psi_{+1}^{*}(z)+\Psi_{0}^{*}(z) \Psi_{-1}(z) \\
& \xi_{-}(z)=\xi_{+}^{*}(z)
\end{aligned}
$$

For random $p$ - layer inside the RTS the solution of equation (9) is found as:

$$
\varphi(z, t)=\sum_{p=1}^{5}\left[\varphi_{s t}^{(p)}(z)+\varphi_{-}^{(p)}(z) e^{i \omega t}+\varphi_{+}^{(p)}(z) e^{-i \omega t}\right]\left[\theta\left(z-z_{p-1}\right)-\theta\left(z-z_{p}\right)\right]
$$

From the equation (9), taking account (11) with keeping the summands of the first degree we obtain:

$$
\begin{aligned}
& \frac{\partial^{2} \varphi_{s t}^{(p)}(z)}{\partial z^{2}}=-\frac{4 \pi e n_{0}}{\varepsilon_{p}} \xi_{0}^{(p)}(z) \\
& \frac{\partial^{2} \varphi_{ \pm}^{(p)}(z)}{\partial z^{2}}=-\frac{4 \pi e n_{0}}{\varepsilon_{p}} \xi_{\mp}^{*(p)}(z)
\end{aligned}
$$

the solutions of which have the appearance:

$$
\begin{gathered}
\varphi_{s t}^{(p)}(z)=-\frac{4 \pi e n_{0}}{\varepsilon_{p}} \int_{0}^{z} \int_{0}^{z_{1}} \xi_{0}^{(p)}\left(z_{2}\right) d z_{1} d z_{2}+C_{1}^{(p)}\left(z-z_{p-1}\right)+C_{2}^{(p)} \\
\varphi_{ \pm}^{(p)}(z)=-\frac{4 \pi e n_{0}}{\varepsilon_{p}} \int_{0}^{z} \int_{0}^{z_{1}} \xi_{\mp}^{(p)}\left(z_{2}\right) d z_{1} d z_{2}+C_{1}^{\mp(p)}\left(z-z_{p-1}\right)+C_{2}^{\mp(p)}
\end{gathered}
$$

They determine potential $\varphi_{s t}^{(p)}(z)$ caused by static spacial charge, and potentials, which are caused by spacial dynamic charge in the case of electronic transition with the absorption $\varphi_{+}^{(p)}(z)$ and the emission of photons $\varphi_{-}^{(p)}(z)$ correspondingly.

All unknown coefficients $C_{1}^{(p)} ; C_{2}^{(p)} ; C_{1}^{\mp(p)} ; C_{2}^{\mp(p)}$ are definitely determined from the continuity conditions of the potential and the vector of electric displacement field on all RTS hetero-boundaries:

$$
\left[\begin{array}{l}
\varphi_{p}\left(z_{p}, t\right)=\varphi_{p+1}\left(z_{p}, t\right) \\
\left.\varepsilon_{p} \frac{\partial \varphi_{p}(z, t)}{\partial z}\right|_{z=z_{p}}=\left.\varepsilon_{p+1} \frac{\partial \varphi_{p+1}(z, t)}{\partial z}\right|_{z=z_{p}} .
\end{array}\right.
$$


Taking account (11) from the system of equations (16) we obtain the boundary conditions for potentials $\varphi_{s t}^{(p)}(z), \varphi_{ \pm}^{(p)}(z)$ :

$$
\begin{aligned}
& \left\{\begin{array}{l}
\varphi_{s t}^{(p)}\left(z_{p}\right)=\varphi_{s t}^{(p+1)}\left(z_{p}\right) ; \\
\left.\varepsilon_{p} \frac{\partial \varphi_{s t}^{(p)}(z)}{\partial z}\right|_{z=z_{p}}=\left.\varepsilon_{p+1} \frac{\partial \varphi_{s t}^{(p+1)}(z)}{\partial z}\right|_{z=z_{p}},
\end{array}\right. \\
& \left\{\begin{array}{l}
\varphi_{ \pm}^{(p)}\left(z_{p}\right)=\varphi_{ \pm}^{(p+1)}\left(z_{p}\right) \\
\left.\varepsilon_{p} \frac{\partial \varphi_{ \pm}^{(p)}(z)}{\partial z}\right|_{z=z_{p}}=\left.\varepsilon_{p+1} \frac{\partial \varphi_{ \pm}^{(p+1)}(z)}{\partial z}\right|_{z=z_{p}} .
\end{array}\right.
\end{aligned}
$$

On the left and on the right of the RTS boundaries for the potentials caused by the static and dynamic charges, the conditions of their disappearance must be satisfied:

$$
\begin{array}{cl}
\left.\varphi_{s t}(z)\right|_{z \rightarrow 0}=0 ; & \left.\varphi_{s t}(z)\right|_{z \rightarrow z_{5}}=0 \\
\left.\varphi_{ \pm}(z)\right|_{z \rightarrow 0}=0 ; & \varphi_{ \pm}(z)_{z \rightarrow z_{5}}=0 .
\end{array}
$$

Taking into account (11) and (8) from the full Schrödinger equation after equating the coefficients at $e^{ \pm i \omega t}$ and zero order values, we obtain the equations:

$$
\begin{gathered}
\left(-\frac{\hbar^{2}}{2} \frac{\partial}{\partial z} \frac{1}{m(z)} \frac{\partial}{\partial z}+U(z)+e \varphi_{s t}(z)-E\right) \Psi_{0}(z)=0 \\
\left(-\frac{\hbar^{2}}{2} \frac{\partial}{\partial z} \frac{1}{m(z)} \frac{\partial}{\partial z}+U(z)+e \varphi_{s t}(z)-\hbar\left(\omega \pm \omega_{0}\right)\right) \Psi_{ \pm 1}(z)=e\left(E\left[z \theta(z)+\left(z_{5}-z\right) \theta\left(z-z_{5}\right)\right]-\varphi_{ \pm}(z)\right) \Psi_{0}(z) .
\end{gathered}
$$

The obtained Schrödinger equations (18), (19) together with the Poisson's equations (12), (13) form the system of self-consistent equations, while solving this system of equations in order to simplify the bulky equations, let as omit the symbol $E$ in $\Psi_{0}(z)$ and $\varphi_{s t}(z)$ these two functions depend on, caused in opened nanosystem. at the first the solution of equation (18) is found in zero approach without taking into account the static spacial charge, substituting in it $\varphi_{s t}(z)=0$. Taking into account the analytical complexity of the equations (18) and (19), they are worth being solved due to linear approxima- tion of the effective potential $U_{\text {eff }}(z)=U(z)$ on all the RTS layers. Then the approximated effective potential for electron has the appearance:

$$
\tilde{U}_{\text {eff }}(z)=\sum_{p=1}^{5} \sum_{l=0}^{N} U_{\text {eff }}\left(z_{p_{l}}\right)\left[\theta\left(z-z_{p_{l}}\right)-\theta\left(z-z_{p_{l+1}}\right)\right],
$$

Now, the solution of the stationary Schrödinger equation (20), found with the necessary accuracy, is obtains as:

$$
\begin{aligned}
& \Psi_{0}(z)=\Psi_{0}^{(0)}(z) \theta(-z)+\Psi_{0}^{(6)}(z) \theta\left(z-z_{5}\right)+\sum_{p=1}^{5} \sum_{l=0}^{N} \Psi_{0 l}^{(p)}(z)\left[\theta\left(z-z_{p_{l}}\right)-\theta\left(z-z_{p_{l+1}}\right)\right]= \\
& =\left(A_{0}^{(0)} e^{i k_{0}^{(0)} z}+B_{0}^{(0)} e^{-i k_{0}^{(0)} z}\right) \theta(-z)+A_{0}^{(6)} e^{i k_{0}^{(6)}\left(z-z_{5}\right)} \theta\left(z-z_{5}\right)+ \\
& +\sum_{p=1}^{5} \sum_{l=0}^{N}\left[A_{0 l}^{(p)} e^{i k_{0}^{(l)}\left(z-z_{p_{l}}\right)}+B_{0 l}^{(p)} e^{-i k_{0}^{(l)}\left(z-z_{p_{l}}\right)}\right]\left[\theta\left(z-z_{p_{l}}\right)-\theta\left(z-z_{p_{l+1}}\right)\right],
\end{aligned}
$$

where

$$
k_{0}^{\left(p_{l}\right)}=k_{0}^{\left(p_{l}\right)}\left(z_{p_{l}}\right)= \begin{cases}\hbar^{-1} \sqrt{2 m_{w}\left(E+e F z_{p_{l}}\right)} ; & \text { wells } \\ \hbar^{-1} \sqrt{2 m_{b}\left(E-U+e F z_{p_{l}}\right)}, & \text { barriers }\end{cases}
$$

Substituting the solution (21) in the Poisson's equation (12), taking into account (20) the potential $\varphi_{s t_{0}}(z)$ is found. Further the potential $\varphi_{s t_{0}}(z)$ is linearized:

$$
\varphi_{s t 0}(z)=\sum_{p=1}^{5} \sum_{l=0}^{N} \varphi_{s t}^{(p)}\left(z_{p_{l}}\right)\left[\theta\left(z-z_{p_{l}}\right)-\theta\left(z-z_{p_{l+1}}\right)\right]
$$

where in the expressions (20) and (22):

$$
\begin{aligned}
& \Psi_{\mathrm{I}}(z)=\left(A_{\mathrm{I}}^{(0)} e^{i k_{0}^{(0)} z}+B_{\mathrm{I}}^{(0)} e^{-i k_{0}^{(0)} z}\right) \theta(-z)+A_{\mathrm{I}}^{(6)} e^{i k_{0}\left(z-z_{5}\right)} \theta\left(z-z_{5}\right)+ \\
& +\sum_{p=1}^{5} \sum_{l=0}^{N}\left[A_{\mathrm{I} l}^{(p)} e^{i K_{\mathrm{I}}^{(l)}\left(z-z_{p_{l}}\right)}+B_{\mathrm{I} l}^{(p)} e^{-i K_{\mathrm{I}}^{(l)}\left(z-z_{p_{l}}\right)}\right]\left[\theta\left(z-z_{p_{l}}\right)-\theta\left(z-z_{p_{l+1}}\right)\right],
\end{aligned}
$$

$N$ - is the number of mesh intervals in the $P$-th RTS layer.

Having substituted the potential $\varphi_{s t_{0}}(z)$ in (18), we obtain the equation:

$\left(-\frac{\hbar^{2}}{2} \frac{\partial}{\partial z} \frac{1}{m(z)} \frac{\partial}{\partial z}+U(z)+e \varphi_{s t_{0}}(z)-E\right) \Psi_{\mathrm{I}}(z)=0$,

for the wave function of the first approximation $\Psi_{1}(z)$. Its solution is:

where 


$$
K_{\mathrm{I}}^{\left(p_{l}\right)}=K_{\mathrm{I}}^{\left(p_{l}\right)}\left(z_{p_{l}}\right)= \begin{cases}\hbar^{-1} \sqrt{2 m_{w}\left(\hbar \omega_{0}-e \tilde{\varphi}\left(z_{p_{l}}\right)\right)} ; & \text { wells } \\ \hbar^{-1} \sqrt{2 m_{b}\left(\hbar \omega_{0}-U-e \tilde{\varphi}\left(z_{p_{l}}\right)\right)}, & \text { barriers }\end{cases}
$$

The found in the first iteration order the stationary wave function $\Psi_{\mathrm{T}}(z)$ makes possible to obtain the potential of the static spatial charge $\varphi_{s t_{1}}(z)$ of the first order as well due to the already applied algorithm.

Self-consistent solution of the equation system (18) and (12) is obtained with the necessary accuracy in the $L$ - iteration cycle, if the relationship is satisfied:

$$
\left|\varphi_{s t_{L-1}}(z)-\varphi_{s t_{L}}(z)\right| / \varphi_{s t_{L}}(z)<<1 .
$$

Then, having used the omitted earlier energy sign $(E)$, we will obtain:

$$
\Psi_{0}(E, z) \approx \Psi_{L}(z), \varphi_{s t}(E, z) \approx \varphi_{s t_{L}}(z) .
$$

The found wave function $\Psi_{0}(E, z)$ makes possible to calculate analytical function of transparency coefficient of nanostructure:

$$
D(E)=\left|\frac{A_{L}^{(6)}}{A_{L}^{(0)}}\right|^{2} .
$$

Wave function $\Psi_{0}(E, z)$ makes possible to find similarly the self-consistent solution of equation systems (19) and (13). In the zero iteration order it is assumed, $\varphi_{ \pm}(z)=0$ can be put in equation (19). Then the solutions of these equations with the linearized potential $\tilde{\varphi}_{s t}(z)$ are found as:

$$
\Psi_{ \pm 1}^{0}(z)=\Psi_{0 \pm}(z)+\Phi_{0 \pm}(z) .
$$

Here

$$
. \Psi_{0 \pm}(z)=B_{0 \pm}^{(0)} e^{-i k_{ \pm}^{(0)} z} \theta(-z)+A_{0 \pm}^{(6)} e^{i k_{ \pm}^{(6)}\left(z-z_{5}\right)} \theta\left(z-z_{5}\right)+\sum_{p=1}^{5} \sum_{l=1}^{N}\left[A_{0 \pm}^{(p, l)} e^{i K_{ \pm}^{(p, l)}\left(z-z_{p l}\right)}+B_{0 \pm}^{(p, l)} e^{-i K_{ \pm}^{(p, l)}\left(z-z_{p l}\right)}\right]\left[\theta\left(z-z_{p_{l}}\right)-\theta\left(z-z_{p_{l+1}}\right)\right]
$$

- are solutions of homogenous equations (21),

$$
\Phi_{0 \pm}(z)=\sum_{p=1}^{5} \sum_{l=0}^{N}\left(\mp \frac{e € z}{\hbar \omega} \Psi_{0 l}^{(p)}(z)+\frac{e €}{m_{p_{l}} \omega^{2}} \frac{d \Psi_{0 l}^{(p)}(z)}{d z}\right)\left[\theta\left(z-z_{p_{l}}\right)-\theta\left(z-z_{p_{l+1}}\right)\right]+\frac{e € z_{5}}{\hbar \omega} \Psi_{0}^{(6)}(z) \theta\left(z-z_{5}\right) .
$$

- partial solutions of correspondingly inhomogeneous equations (21), where:

$m_{p_{l}}=\left\{\begin{array}{l}m_{w} \\ m_{b}\end{array} ; k_{ \pm}^{(0)}=k_{ \pm}^{(6)}=\hbar^{-1} \sqrt{2 m_{w}\left(\hbar\left(\omega_{0} \pm \omega\right)\right)} ;\right.$

$K_{ \pm}^{(p, l)}=K_{ \pm}^{(p, l)}\left(z_{p_{l}}\right)= \begin{cases}\sqrt{\left.2 m_{w}\left(\hbar\left(\omega_{0} \pm \omega\right)-e \varphi z_{p_{l}}\right)\right)} ; & \text { wells } \\ \sqrt{2 m_{b}\left(\hbar\left(\omega_{0} \pm \omega\right)-U-e \varphi\left(z_{p_{l}}\right)\right)} & \text { barriers }\end{cases}$

tion of the static potential, the analytical calculation of the dynamic component of the potential $\varphi_{0 \pm}(z)$ in zero iteration order is carried out. As result we obtain:

$$
\varphi_{0 \pm}(z)=\sum_{p=1}^{5} \sum_{l=0}^{N} \varphi_{ \pm}^{(p, l)}\left(z_{p_{l}}\right)\left[\theta\left(z-z_{p_{l}}\right)-\theta\left(z-z_{p_{l+1}}\right)\right],
$$

where

Similar to the mentioned above scheme of calcula-

$$
\begin{aligned}
& \varphi_{ \pm_{w, b}}^{(p, l)}(z)=C_{1}^{ \pm(p, l)}\left(z-z_{p_{l-1}}\right)+C_{2}^{ \pm(p, l)}+\frac{4 \pi e n_{0}}{\varepsilon_{w, b}} \times\left\{\frac{A_{0}^{(p, l)} A_{ \pm}^{*(p, l)} e^{i\left(K_{0}^{(p, l)}-K_{ \pm}^{(p, l)}\right)\left(z-z_{p l}\right)}+B_{0}^{(p, l)} B_{ \pm}^{*(p, l)} e^{-i\left(K_{0}^{(p, l)}-K_{ \pm}^{(p, l)}\right)\left(z-z_{p l}\right)}}{\left(K_{0}^{(p, l)}-K_{ \pm}^{(p, l)}\right)^{2}}+\right. \\
& +\frac{A_{0}^{(p, l)} B_{ \pm}^{*(p, l)} e^{i\left(K_{0}^{(p, l)}+K_{ \pm}^{(p, l)}\right)\left(z-z_{p l}\right)}+B_{0}^{(p, l)} A_{ \pm}^{*(p, l)} e^{-i\left(K_{0}^{(p, l)}+K_{ \pm}^{(p, l)}\right)\left(z-z_{p l}\right)}}{\left(K_{0}^{(p, l)}+K_{ \pm}^{(p, l)}\right)^{2}}+ \\
& +\frac{A_{0}^{*(p, l)} A_{\mp}^{(p, l)} e^{-i\left(K_{0}^{(p, l)}-K_{ \pm}^{(p, l)}\right)\left(z-z_{\left.p_{l}\right)}\right)}+B_{0}^{*(p, l)} B_{\mp}^{*(p, l)} e^{i\left(K_{0}^{(p, l)}-K_{ \pm}^{(p, l)}\right)\left(z-z_{p_{l}}\right)}}{\left(K_{0}^{(p, l)}-K_{\mp}^{(p, l)}\right)^{2}}-\frac{B_{0}^{*(p, l)} A_{\mp}^{*(p, l)} e^{i\left(K_{0}^{(p, l)}+K_{\mp}^{(p, l)}\right)\left(z-z_{\left.p_{l}\right)}\right)}+A_{0}^{*(p, l)} B_{\mp}^{*(p, l)} e^{-i\left(K_{0}^{(p, l)}+K_{ \pm}^{(p, l)}\right)\left(z-z_{\left.p_{l}\right)}\right)}}{\left(K_{0}^{(p, l)}+K_{\mp}^{(p, l)}\right)^{2}}- \\
& \left.-\frac{i e \epsilon}{2 K_{0}^{(p, l)} m_{l} \omega^{2}}\left(A_{0}^{(p, l)} B_{0}^{*(p, l)} e^{2 i K_{0}^{(p, l)}\left(z-z_{p_{l}}\right)}-B_{0}^{(p, l)} A_{0}^{*(p, l)} e^{-2 i K_{0}^{(p, l)}\left(z-z_{\left.p_{l}\right)}\right)}\right)\right\} .
\end{aligned}
$$

Conditions of continuity of wave functions and their flows density on all boundaries define the necessary coefficients $(A, B)$. As the result of $L$ - iteration the functions $\Psi_{0}(z), \Psi_{ \pm 1}(z)$ are definitely found, hence, the total wave function $\Psi(z, t)$.

Using the found wave functions similar to those as in the works $[4,12]$, the calculation of the electron currents density due to RTS is carried out:

$$
j(E \pm \hbar \omega, z)=\frac{i e \hbar n_{0}}{2 m_{w}}\left(\Psi_{ \pm 1}(E, z) \frac{d \Psi_{ \pm 1}^{*}(E, z)}{d z}-\Psi_{ \pm 1}^{*}(E, z) \frac{d \Psi_{ \pm 1}(E, z)}{d z}\right),
$$


which are in the proportion to the corresponding parts of the active dynamic conductivity $\sigma^{ \pm}(E, \Omega)$.

The calculated full active conductivity of RTS $\sigma(E, \Omega)$ is defined by the sum of two partial components:

$$
\sigma(E, \Omega)=\sigma^{+}(E, \Omega)+\sigma^{-}(E, \Omega),
$$

where

$$
\begin{gathered}
\sigma^{+}(E, \Omega)=\frac{\hbar \Omega n_{0}}{2 m_{w} z_{5} \epsilon^{2}}\left(k_{+1}^{(6)}\left|A_{+1}^{(6)}\right|^{2}-k_{-1}^{(6)}\left|A_{-1}^{(6)}\right|^{2}\right) \\
\sigma^{-}(E, \Omega)=\frac{\hbar \Omega n_{0}}{2 m_{w} z_{5} \epsilon^{2}}\left(k_{+1}^{(0)}\left|B_{+1}^{(0)}\right|^{2}-k_{-1}^{(0)}\left|B_{-1}^{(0)}\right|^{2}\right) .
\end{gathered}
$$

As to their physical content these partial components are formed by the electronic flows, directed to the input $\left(\sigma^{+}(E, \Omega)\right)$ and output $\left(\sigma^{-}(E, \Omega)\right)$ of the nanostructure relatively to the initial direction of electron flow.

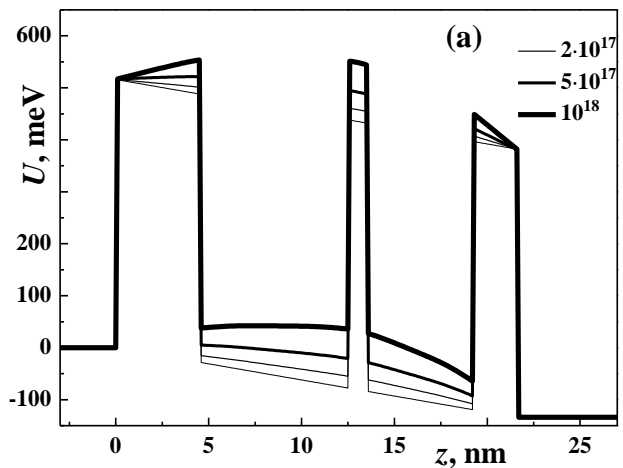

Fig. 2 - Potential profile of RTS renormalized by static charge laser transitions $3 \rightarrow 2,2 \rightarrow 1$ i $3 \rightarrow 1$ on $z$

renormalized by static charge is presented, calculated for different values of the electron concentration in the beam falling on RTS. As it is seen from the Figure, with greater of concentration of electrons, the potential profile of RTS is deformed greater, the heights of the potential barriers being greater and the bottom of the conductivity zone of the input and output quantum wells being raised. As it will be shown further, the identified effect is revealed as the sufficient effect on spectral parameters of the quasi-stationary states of electron in the investigated RTS - its resonance energy and widths.

In Fig. $2 b$ the dependences of the potential values $\varphi_{\text {dyn }}$ on the geometric sizes of RTS $z$, found by the dynamic charge in the laser quantum transitions $3 \rightarrow 2$, $2 \rightarrow 1,3 \rightarrow 1$ are presented. As it is seen from the Fig. $2 \mathrm{~b}$ for the calculated potentials $\varphi_{\mathrm{dyn}}$ the relation is satisfied:

$$
\varphi_{\mathrm{dyn}}^{(3,2)}>\varphi_{\mathrm{dyn}}^{(2,1)}>\varphi_{\mathrm{dyn}}^{(3,1)}
$$

Here the nature of the potentials $\varphi_{\mathrm{dyn}}^{(3,2)}, \varphi_{\mathrm{dyn}}^{(2,1)}, \varphi_{\mathrm{dyn}}^{(3,1)}$ dependencies on $z$ are qualitatively the same: values of

\section{DISCCUSSION OF THE RESULTS}

Taking advantage of the developed theory, the calculating of potentials $\varphi_{s t}^{(p)}(z)$ caused by the static spacial charge was carried out, as well as the potentials, defined by the spacial dynamic charge for radiation electronic transitions $\varphi_{+}^{(p)}(z)$.

The calculations where carried on the example of the experimentally realised three-barrier RTS [13] with GaAs - potential wells and $\mathrm{Al}_{0.15} \mathrm{Ga}_{0.85} \mathrm{As}$ - potential barriers with the known physical parameters: $m_{\omega}=0.063 m_{\mathrm{e}} ; \quad m_{b}=0.075 m_{e} ; \quad U=516 \mathrm{meV}$, $F=62 \mathrm{kV} / \mathrm{cm}$, where $m_{e}-$ mass of free electron. Geometric parameters of the examined three-barrier RTS are as follows: the widths of the potential wells $b_{1}=8.0 \mathrm{~nm} ; b_{2}=5.7 \mathrm{~nm}$, the thicknesses of the input, internal, and output potential barriers $\Delta_{1}=4.5 \mathrm{~nm}$; $\Delta_{2}=1.0 \mathrm{~nm} ; \Delta_{3}=2.4 \mathrm{~nm}$ respectively.

In Fig 2a the nanosystem potential profile,

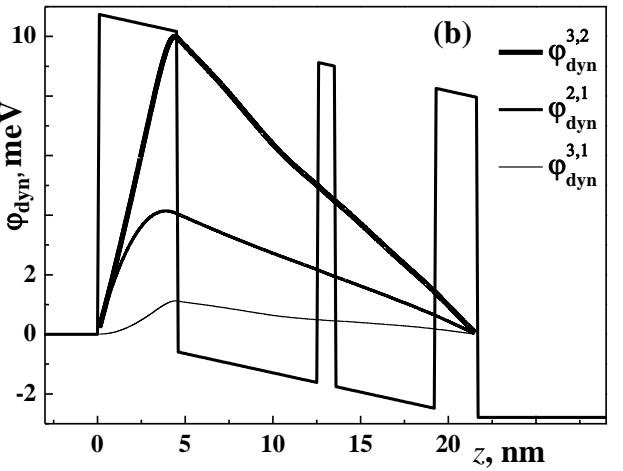

(a) and dependencies of potential, caused by dynamic charge in potentials increase within the left potential barrier, that is, when $0 \leq z \leq \Delta_{1}$, being of the maximal values on the boundary of this barrier with the input potential well. For $0<z \leq b_{1}$ dependencies of potentials on $z$ are declining nature.

In Fig. 3a, b, c, d, e, f the dependencies on the location of the internal potential barrier $b$ in the total potential well at the unvariable other geometric TRS parameters of the energy spectrum of the electron $E_{\mathrm{n}}$, logarithms of resonance width $\Gamma_{\mathrm{n}}$, logarithms of dynamic conductivity, are presented, revealed in the quantum electron transitions from the third to the second and: $\sigma_{32}, \sigma_{32}^{+}, \sigma_{32}^{-} \mathrm{i}$ from the third to the first energy levels $\sigma_{31}, \sigma_{31}^{+}, \sigma_{31}^{-}$. The calculations were performed for the electrons concentration $n=2 \cdot 10^{17} \mathrm{~cm}^{-3}$ within two models: in the model without taking into account the spacial charge effect [12], the results of which are presented in Fig. 3a, b, c (I), and within the model, for which the theory is developed above, and which are presented in Fig. 3d, e, f. (II). The value $b=b_{\exp }$ corresponds the geometric configuration of the experimentally realised RTS [13]. 

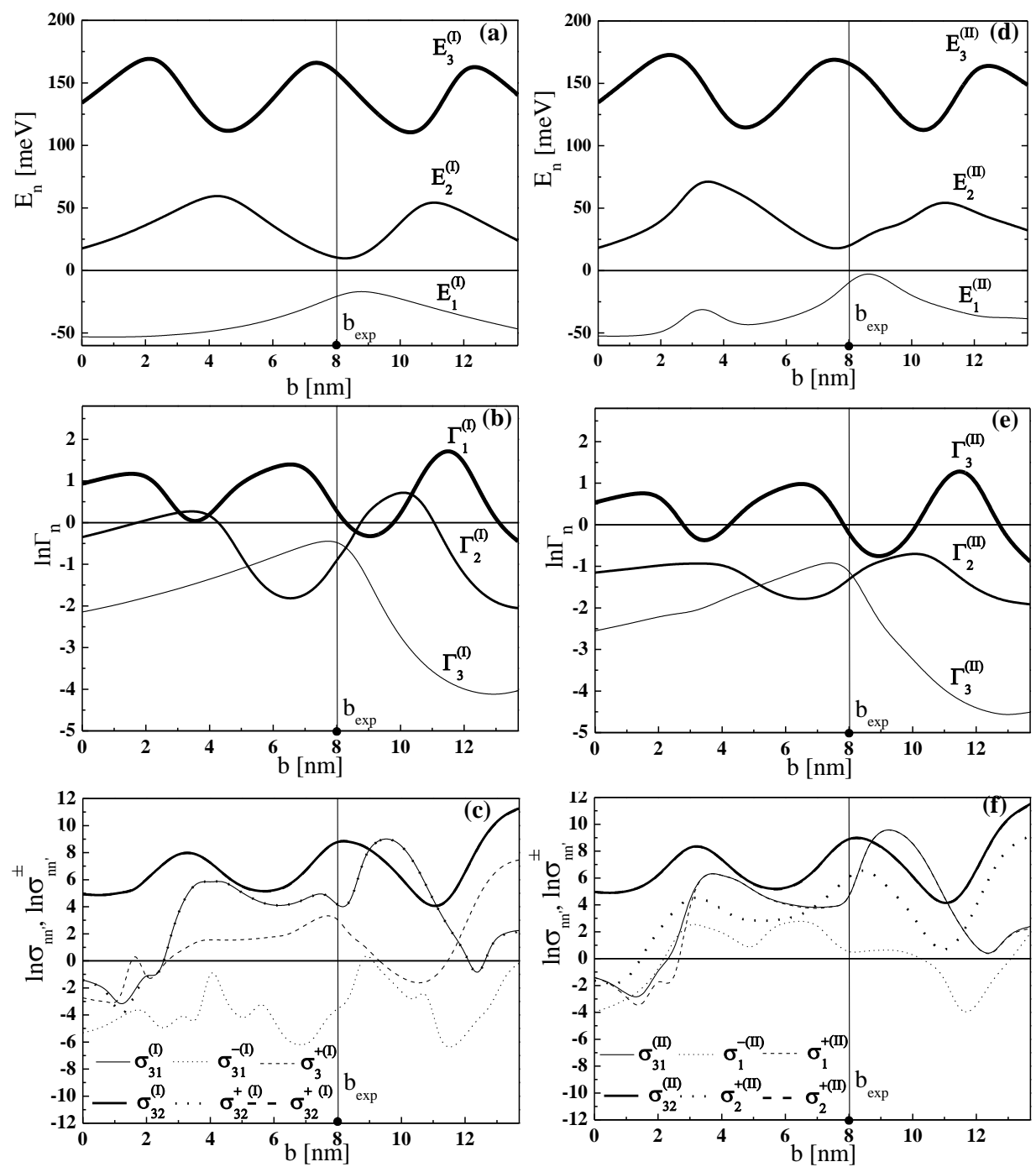

Fig. 3 - Dependencies of energy spectrum $E_{\mathrm{n}}$, logarithms of resonance widths $\Gamma_{\mathrm{n}}$, logarithms dynamic of conductivity of electron and their partial components, revealed in the laser transitions $3 \rightarrow 2\left(\sigma_{32}, \sigma_{32}^{+}, \sigma_{32}^{-}\right)$i $3 \rightarrow 1\left(\sigma_{31}, \sigma_{31}^{+}, \sigma_{31}^{-}\right)$on the position of the internal potential barrier $(b)$ in the total potential well without $(\mathrm{a}, \mathrm{b}, \mathrm{c})$ and with taking into account spatial charge (d, e, f), for carrier concentration $n=2 \cdot 10^{17} \mathrm{~cm}^{-3}$

From Fig. 3a and Fig. 3d it is seen, that the dependencies of the energy spectrum $E_{\mathrm{n}}$ on $b$, which are calculated in two models are qualitatively similar. But in the dependencies of the energy spectrum, which are calculated taking into account the effect of spacial static and dynamic charge, the effects of the increase of the resonance energies of the first quasi-stationary state are revealed, and those of the second - much smaller and that of the third - relatively small at all. As it was mentioned earlier, these effects are caused by the renormalization of potential profile of RTS by the potentials of the static and dynamic spacial charges. For the experimentally realised geometric configuration $b_{\text {exp }}$ in both models we obtain:

$$
\begin{aligned}
& E_{1}^{(\mathrm{I})}=-20.553 \mathrm{meV} ; E_{2}^{(\mathrm{I})}=10.003 \mathrm{meV} ; \\
& E_{3}^{(\mathrm{I})}=158.624 \mathrm{meV} \quad \text { and } \quad E_{1}^{(\mathrm{II})}=-8.962 \mathrm{meV} ; \\
& E_{2}^{(\text {II) }}=18.879 \mathrm{meV} ; \quad E_{3}^{(\mathrm{II})}=163.736 \mathrm{meV} .
\end{aligned}
$$

Thus, for both models the value of the electromagnetic field energy, generated in the quantum transition
$3 \rightarrow 2: \quad \Omega_{32}^{(\mathrm{I})}=148,621 \mathrm{meV}$ and $\Omega_{32}^{(\mathrm{II})}=144,857 \mathrm{meV}$ is different from experimentally realised $\Omega_{32}^{\exp }=146.161 \mathrm{meV}$ by $1.7 \%$ and $0.9 \%$ correspondingly.

From Fig. 3b and Fig. 3e it is seen, that the dependencies of resonance width of the quasi-stationary states of electron $\Gamma_{n}$ on $b$ is presented. It should be noted, that in spite of the quantitive similarity of the resonance width dependencies, calculated in both models, in the model, which takes into account the contribution of spacial charge, the value of the resonance width is smaller, relatively to the model, which does not take into account the spacial charge, the value of resonance width $\Gamma_{n}$ become smaller, when the quantum number $n$ becomes larger. Thus, for the experimentally realized geometric configuration $b_{\text {exp }}$ in both models we obtain:

$\Gamma_{1}^{(\mathrm{I})}=0.638 \mathrm{meV} ; \Gamma_{2}^{(\mathrm{I})}=0.409 \mathrm{meV} ;$

$\Gamma_{3}^{(\mathrm{I})}=1.295 \mathrm{meV}$

and $\Gamma_{1}^{(\mathrm{II})}=0.352 \mathrm{meV} ; \Gamma_{2}^{(\mathrm{II})}=0.269 \mathrm{meV}$; 


$$
\Gamma_{3}^{(\mathrm{II})}=0.780 \mathrm{meV} \text {. }
$$

As the electron life-time in the quasi-stationary state is connected with the resonance width of this state by the relation $\tau_{n}=\hbar / \Gamma_{n}$, the spacial charge causes the increase of the electron life-time in two operational quasi-stationary states almost in two times. Thus, we may conclude the first, that for the sufficient electron concentration $n$, the effect of the spacial charge is of the dissipation nature, causing breaking of the nanodevices coherent state.

In Fig. 3c and Fig. $3 \mathrm{f}$ the dependencies of the logarithms of dynamic conductivities on the $b$-values are presented, which are revealed in the laser electron quantum transitions $3 \rightarrow 2$ and $3 \rightarrow 1$, and their partial components: $\sigma_{32}, \sigma_{32}^{+}, \sigma_{32}^{-}$and $\sigma_{31}, \sigma_{31}^{+}, \sigma_{31}^{-}$. It is seen from these Figures, that when $b$ varies, the absolute values of the conductivities $\sigma_{32}$ and $\sigma_{31}$ stay almost the same for both models. But in the model, which takes into account the effect of the spacial charge, the partial components of conductivity $\sigma_{32}^{+}, \sigma_{31}^{+}$, which are defined by the direct electron flow, decrease. The partial components $\sigma_{32}^{-}, \sigma_{31}^{-}$, defined by the electron flow in the opposite direction, increase. It should be noted, that this effect sufficiently revealed seen for the quantum transition $3 \rightarrow 2$, which can be explained by satisfying the relation (44). Here, for the experimentally realized configuration of RTS $b_{\exp }$, we obtain:

$$
\sigma_{32}^{(\mathrm{I})}=-7397.14 \mathrm{~S} / \mathrm{cm}, \sigma_{32}^{+(\mathrm{I})}=-7342.96 \mathrm{~S} / \mathrm{cm},
$$

$$
\begin{aligned}
& \sigma_{32}^{-(\mathrm{I})}=-54.18 \mathrm{~S} / \mathrm{cm}, \sigma_{31}^{(\mathrm{I})}=-54.15 \mathrm{~S} / \mathrm{cm}, \\
& \sigma_{31}^{+(\mathrm{I})}=-54.12 \mathrm{~S} / \mathrm{cm}, \sigma_{31}^{-(\mathrm{I})}=-0.03 \mathrm{~S} / \mathrm{cm} \text { and } \\
& \sigma_{32}^{(\mathrm{II})}=-7423.21 \mathrm{~S} / \mathrm{cm}, \sigma_{32}^{+(\mathrm{II})}=-6938.64 \mathrm{~S} / \mathrm{cm}, \\
& \sigma_{32}^{-(\mathrm{II})}=-484.57 \mathrm{~S} / \mathrm{cm}, \sigma_{31}^{(\mathrm{II})}=-56.17 \mathrm{~S} / \mathrm{cm}, \\
& \sigma_{31}^{+(\mathrm{II})}=-55.52 \mathrm{~S} / \mathrm{cm}, \sigma_{31}^{-(\mathrm{II})}=-0.65 \mathrm{~S} / \mathrm{cm} .
\end{aligned}
$$

Thus, we can conclude, that the dynamic charge causes the redistribution of the partial components of the dynamic conductivity, formed in the laser transitions $3 \rightarrow 1$ and $3 \rightarrow 2$ in its total value. Here, the component of conductivity $\sigma^{+}$, found on the direct electron flow, decreases, and the component $\sigma^{-}$found by the flow in the opposite direction, increases. According to the work [13], this effect is the dissipative factor, that is why it must be taken into account in investigating of the electron tunneling transport through the multilayer RTS.

\section{CONCLUSIONS}

Quantum-mechanical theory of the active dynamic conductivity of electrons by the three-barrier RTS with the applied constant electric field, taking into account the effect of the spacial dynamic and static charges, has been developed. It was shown, that the effect of spacial charge reveals itself in the displacement of the energy spectrum of electron towards the greater energies, in crease of the electrons life time in the quasi-stationary states and the increase of the partial component of conductivity, which is defined by the electron flow, which is directed to the RTS input.

\title{
Вплив просторового заряду на тунелювання електронів та їх провідність резонансно-тунельними структурами в постійному електричному полі
}

\author{
I.В. Бойко, М.Р. Петрик
}

Тернопільський національний технічний університет ілені Івана Пулюл, вул. Руська, 56, 46001 Тернопіль, Україна

\begin{abstract}
3 використанням моделі прямокутних потенціальних ям і бар'єрів розвинена квантово-механічна теорія спектральних параметрів і динамічної провідності електронів, взаемодіючих із створюваним ними полем просторового заряду у відкритій плоскій резонансно-тунельній структурі 3 постійним електричним полем. Досліджено вплив просторового заряду на провідність експериментально реалізованої наноструктури як активної області квантового каскадного лазера для різних концентрацій електронів в падаючому на резонансно-тунельну структуру пучку.
\end{abstract}

Ключові слова: Резонансно-тунельна структура, Квантовий каскадний лазер, Статичний заряд, Динамічний заряд, Динамічна провідність.

\section{Влияние пространственного заряда на туннелирование электронов и их проводимость резонансно-туннельными структурами в постоянном электрическом поле}

\author{
И.В. Бойко, М.Р. Петрик
}

Тернопольский национальный технический университет илени Ивана Пулюя, ул. Руська, 56, 46001, Тернополь, Украина 
С использованием модели прямоугольных потенциальных ям и барьеров развита квантовомеханическая теория спектральных параметров и динамической проводимости электронов, взаимодействующих с создаваемым ими полем пространственного заряда в открытой плоской резонанснотуннельной структуре с постоянным электрическим полем. Исследовано влияние пространственного заряда на проводимость әкспериментально реализованной наноструктуры как активной области квантового каскадного лазера для различных концентраций электронов в падающем на резонанснотуннельную структуру пучке.

Ключевые слова: Резонансно-туннельная структура, Квантовый каскадный лазер, Статический заряд, Динамический заряд, Динамическая проводимость.

\section{REFERENCES}

1. D. Turčinková, M. I. Amanti, G. Scalari, M. Beck and J. Faist, Appl. Phys. Lett. 106, 131107 (2015).

2. J. M. Wolf, S. Riedi, M. G. Süess, M. Beck and J. Faist, Optics Express. 24, 662 (2016).

3. D. Hofstetter, F. R. Giorgetta, E. Baumann, Q. Yang, C. Manz, and K. Kohler, Appl. Phys. Lett. 93, 221106 (2008).

4. Ju. O. Seti, M. V. Tkach, I. V. Boyko, J. Optoelectron. Adv. M. 14, 393 (2012).

5. Ju. O. Seti, M. V. Tkach, M. V. Pan'kiv, J. Phys. Stud. 20, 1703 (2016).

6. X. Gao, D. Botez, I. Knezevic, J. Appl. Phys. 103, 073101 (2008).

7. M. V. Tkach, Ju. O. Seti, Y. B. Grynyshyn, O. M. Voitsekhivska, Acta Phys. Pol. A. 128, 343-343 (2015).

8. O. O. Celleka, S. Memis, U. Bostanci, S. Ozer, C. Besikci, Physica E. 24, 318 (2004).

9. V. Ryzhii, M. Ryzhii, H. C. Liu, J. Appl. Phys. 91, 5887 (2002).

10. A. B. Pashkovskii, Semiconductors 34, 334 (2000).

11. A. B. Pashkovskii, Semiconductors 43, 1316 (2009).

12. M. V. Tkach, Ju. O. Seti, I. V. Boyko, O. M. Voitsekhivska, Condens. Matter. Phys. 13, 33701 (2013).

13. D. Hofstetter, M. Beck, T. Aellen, J. Faist, Appl.Phys. Lett. 78, 396 (2001). 